\title{
Impotence: diagnosis and management of male erectile dysfunction
}

\author{
Roger S Kirby
}

Impotence is defined as the persistent failure to develop erections of sufficient rigidity for penetrative sexual intercourse. The disorder is strongly related to age, with an estimated prevalence of $2 \%$ at age 40 years rising to $25-30 \%$ by the age of $65 .{ }^{1}$ Although no data are available on the prevalance of impotence in men over 75 , it is probably over $50 \%$. As the proportion of men aged over 65 is predicted to more than double in many developed countries in the next 30 years and the incidence of diabetes, which is one of the commonest causes of impotence, ${ }^{2}$ is also rising, doctors are likely to spend more time in the diagnosis and management of erectile dysfunction.

Although impotence does not affect life expectancy, it can have a strong negative effect on well being and quality of life. It also often affects a man's interactions with his family and associates. The problem tends to be compounded by unrealistic expectations of continuing sexual prowess, partly as a result of most men's reluctance to admit to or even discuss the problem with their peers. Some men even hide their difficulties with erections from their partner, who may make the problem worse by misinterpreting the apparent lack of sexual interest as a sign of unfaithfulness.

Once the problem is faced, however, some couples are happy simply to accept impotence as an inevitable consequence of the passage of years. But increasing numbers of men aged 50-75, especially those with younger partners, are now requesting medical help to resolve the problem. Recent advances in our ability to diagnose and treat a number of specific causes of erectile dysfunction have improved the prospects for the durable restoration of sexual function, although many impotent men, and their general practitioners, are still unaware of this.

\section{Normal mechanisms of erection}

Erection of the penis depends on the adequate filling of the paired corpora cavernosa with blood at systolic pressure or slightly above. Arterial blood enters from the paired cavernosal arteries, which are terminal branches of the internal iliac arteries. Numerous corkscrew shaped helicine arteries branch off each cavernosal artery within the corpora and empty into the lacunar spaces. Erection occurs when the tonically contracted cavernosal and helicine arteries relax, increasing blood flow to the lacunar spaces and resulting in engorgement of the penis.

Relaxation of the trabecular smooth muscle of

St Bartholomew's Hospital, London EC14 7BE

Roger S Kirby, consultant urologist

BMF 1994;308:957-61

\begin{tabular}{|c|}
\hline Summary points \\
\hline $\begin{array}{l}\text { - The public and many doctors are ignorant } \\
\text { about available treatments for impotence }\end{array}$ \\
\hline $\begin{array}{l}\text { - Impotence often has multiple causes, and } \\
\text { diagnostic evaluation should include psycho- } \\
\text { sexual, endocrinological, neurological, and } \\
\text { vascular factors }\end{array}$ \\
\hline $\begin{array}{l}\text { - Intracavernosal injections with muscle } \\
\text { relaxants can be used to produce erections in } \\
\text { most men }\end{array}$ \\
\hline $\begin{array}{l}\text { - Surgical repair of venous leakage or insertion } \\
\text { of inflatable prostheses can help when self } \\
\text { injection is unsatisfactory }\end{array}$ \\
\hline
\end{tabular}

for example, vasoactive intestinal polypeptide-have not been conclusively excluded. Nitric oxide may exert a relaxing effect on the trabecular smooth muscle through stimulating guanylate cyclase to produce cyclic guanosine monophosphate (cGMP), which would then function as a second messenger. ${ }^{3}$

Systemic blood pressure expands the relaxed trabecular walls against the rigid tunica albuginea, compressing the plexus of subtunical venules and restricting venous drainage from the lacunar spaces. Erection is therefore the result of an equilibrium between arterial inflow from the cavernous arteries and the resistance to blood outflow from the lacunar spaces resulting from these veno-occlusive mechanisms (fig 1). Detumescence is accomplished by a reversal of these processes. Increasing sympathetic tone, which is also involved in mediating orgasm and ejaculation, causes the cavernosal and helicine arteries to contract, restricting blood flow into the lacunar spaces. Falling intralacunar pressure then decompresses the subtunical venules, allowing increased venous outflow and restoring the penis to its normal state of flaccidity. ${ }^{45}$

\section{Causes of erectile dysfunction}

The human sexual response is a complex phenomenon, and problems with potency are often multifactorial (box). Broadly, however, the disorders

\section{Causes of impotence}

- Psychological

- Neurological

- Endocrinological

- Vascular (venous or arterial)

- Traumatic

- Iatrogenic (drugs and surgery) 


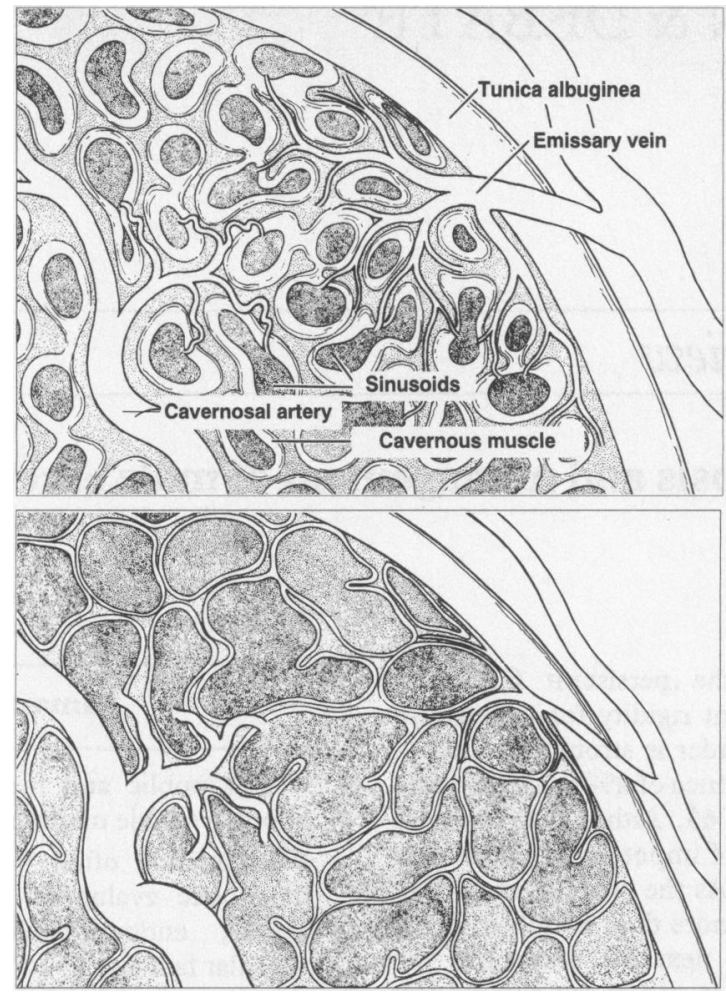

FIG 1-Diagram illustrating distribution of intracavernosal blood in flaccid (top) and erect (bottom) penis

resulting in erectile dysfunction can be subdivided into four groups.

Psychogenic impotence-Just as psychogenic stimuli can result in erection, so the cortex may inhibit penile tumescence. This mainly occurs through the sympathetic nervous system. In nervous men increased sympathetic tone and raised circulating catecholamine concentrations may interfere with the mechanisms of smooth muscle relaxation underlying erection. The problem is self perpetuating: each failure increases the anxiety associated with subsequent attempts at erection. While psychogenic impotence is the commonest cause of intermittent erectile failure in young men, it is usually secondary to some organic dysfunction in middle aged and elderly men. ${ }^{6}$

Endocrinological impotence-Free serum testosterone concentrations fall progressively with age because the testes produce less testosterone and more androgens are removed from the blood by rising concentrations of sex hormone binding globulin. Falling testosterone concentrations are associated with a loss of libido and reduced frequency of erections. Decreased potency may also be an early feature of hyperprolactinaemia. ${ }^{7}$ Raised prolactin concentration is also associated with reduced circulating free testosterone, but simply restorating normal levels of circulating androgens often does not restore sexual function. Hyperprolactinaemia may be associated with drug use, renal failure, or pituitary tumours, or it may be idiopathic.

Neurogenic impotence-Several neurological disorders can impair erectile function, but it is unusual for impaired potency to be the sole manifestation of diseases of the nervous system. Lesions of the cauda equina (due, for example, to a prolapsed intervertebral disc) and peripheral neuropathies affecting the S2-S4 outflow (most commonly due to diabetes mellitus or alcoholism) are associated with impotence. Upper motor neurone lesions resulting from multiple sclerosis or spinal cord injury can also cause impotence by dissociating the sacral reflex arcs from their midbrain, hypothalamic, and cortical controlling mechanisms.
Vascular impotence-The main causes of erectile dysfunction are impaired blood flow to, or excessive leakage from, the penis. Often both are present. In older patients a reduced flow of blood into the penis due to atherosclerotic lesions of the internal iliac, pudendal, and cavernosal arteries is the most common cause. $^{89}$ Reduced perfusion pressure within the lacunar spaces impairs the normal veno-occlusive mechanisms and compounds the difficulty of achieving rigidity by permitting venous leakage into the deep dorsal and crural veins. A few patients have normal arterial inflow but excessive outflow through the subtunical venules into the deep dorsal and crural veins. The causes for this are still unclear, although it may be due to changes in the fibroelastic components of the lacunar trabeculae which prevent adequate compression of the subtunical venules rather than to an abnormality of the deep dorsal or crural veins themselves. Peyronie's disease may also be associated with a venous leak (fig 2).

\section{Diagnostic evaluation}

The first step in evaluating an impotent man is a careful history and physical examination. Men with erectile dysfunction usually have normal libido and unimpaired ejaculatory function. Classically, psychogenic potency problems begin suddenly, occur only in specific situations, and are accompanied by normal nocturnal and early morning erections. By contrast, organic impotence has a gradual onset, is consistently present, and is associated with the loss of early morning erections. A detailed psychosocial and sexual history may reveal long standing relationship difficulties and should establish whether the partner is sympathetic or unsympathetic towards the problem. The main point of the history is to determine the cause of the complaint and the expectations and motivation of the man and his partner for further diagnosis and treatment.

Risk factors for vascular disease should be identified, including a family history, hypertension, alcoholism, smoking, diabetes, and hyperlipidaemia (box). Concomitant neurological disease is usually easily detected. It is relevant not only as a causative factor but also because it may influence the dose of intracavernosal drug selected for diagnosis or treatment.

A drug history is essential since many commonly used drugs have been implicated in erectile dysfunction, although often only in case reports or uncontrolled studies. The mechanism by which most drugs cause impotence is unknown, but there is a clear theoretical basis for this side effect with drugs that interfere with the endocrinological or neurovascular mechanisms underlying erection. Certain anti-

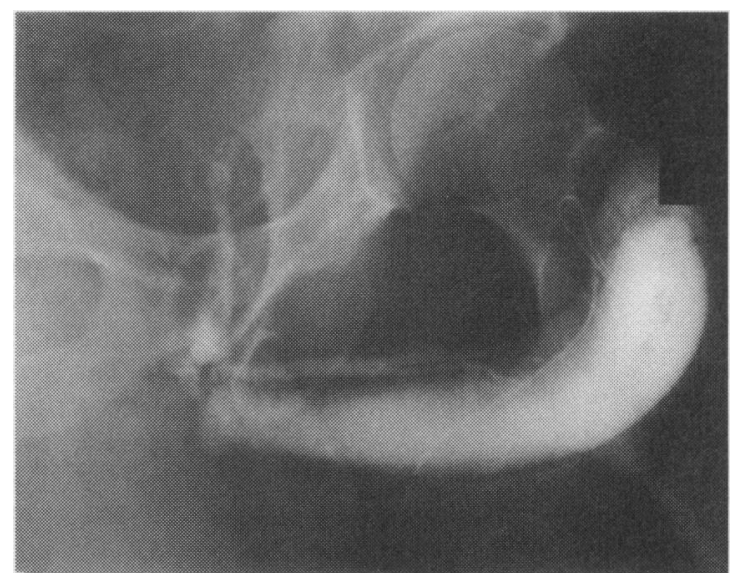

FIG 2 - Cavernogram showing a venous leak through the deep dorsal vein in association with dorsal angulation of the penis resulting from Peyronie's disease 
psychotic and antidepressant drugs interfere with central neurotransmitter pathways subserving potency, and luteinising hormone releasing hormone analogues, oestrogens, and antiandrogens block androgen drive both centrally and peripherally. Several antihypertensive drugs affect the neuromodulation of penile smooth muscle, and these drugs are most commonly implicated in impotence. Many patients with hypertension also have occlusive peripheral vascular disease, which produces suboptimal intralacunar perfusion pressures. Any drug that reduces blood pressure is thus likely to reduce the quality of erections in men with peripheral vascular disease. Other more specific factors also play a part, however, since some antihypertensive drugs-for example, $B$ blockers-are more commonly associated with impotence than other drugs despite similar effects on blood pressure. ${ }^{10}$ In a recent four arm placebo controlled study diuretic therapy was associated with reduced sexual function, an angiotensin converting enzyme inhibitor and channel blocker had no effect, and the $\alpha$ blocking drug doxazosin seemed to enhance sexual function. ${ }^{11}$

\section{PHYSICAL EXAMINATION}

Men with impotence may have several abnormalities of the endocrine, neurological, and vascular systems. The distribution of body fat and facial and pubic hair will give an estimate of the adequacy of androgen concentrations. Examination of the neurological system should include an evaluation of the S2-S4 dermatomes by testing perineal sensation, anal sphincter tone, and the bulbocavernosus reflex. Vascular assessment must include blood pressure, cardiac status, and lower extremity pulses. The penis should be carefully palpated for evidence of Peyronie's plaques and the testes examined to confirm their size, location, and consistency.

\section{SPECIAL INVESTIGATIONS}

Blood should be sent for measurement of concentrations of glucose, creatinine, lipids, thyroid hormones, testosterone, sex hormone binding globulin, luteinising hormone, and prolactin. Testing of nocturnal penile tumescence in hospital ${ }^{12}$ has now been replaced by self administered tests of nocturnal erections such as the snap gauge band ${ }^{13}$ and the Rigiscan device. Neurophysiological testing, although technically feasible, ${ }^{14}$ does not usually alter treatment decisions and is seldom used other than for research. A simple papaverine stimulation test (usually $40 \mathrm{mg}$ with or without $2 \mathrm{mg}$ of phentolamine to potentiate its effect) will distinguish responders from nonresponders and help select candidates for self injection treatment.

Colour Doppler imaging after inducing maximal intracavernous smooth muscle relaxation with papaverine provides detailed information about penile haemodynamics and is particularly useful in distinguishing arterial insufficiency from veno-occlusive dysfunction. ${ }^{15}$ It may also identify impalpable Peyronie's intracavernosal fibrosis. ${ }^{16}$

If colour Doppler ultrasonography suggests an appreciable venous leak reparative venous surgery may sometimes be beneficial. Leakage can be confirmed by pressure flow infusion pharmacocavernosography. Although this investigation sounds complex, it simply measures the flow required to maintain a pharmacologically stimulated erection. If the flow required to create tumescence exceeds $120 \mathrm{ml} / \mathrm{min}$ and the maintenance flow is above $20 \mathrm{ml} / \mathrm{min}$ contrast medium can be injected to find venous leak, which may be from either the deep dorsal vein or the less surgically accessible crural veins (fig 3 ). Selective pudendal pharmacoarteriography is done less often because it is

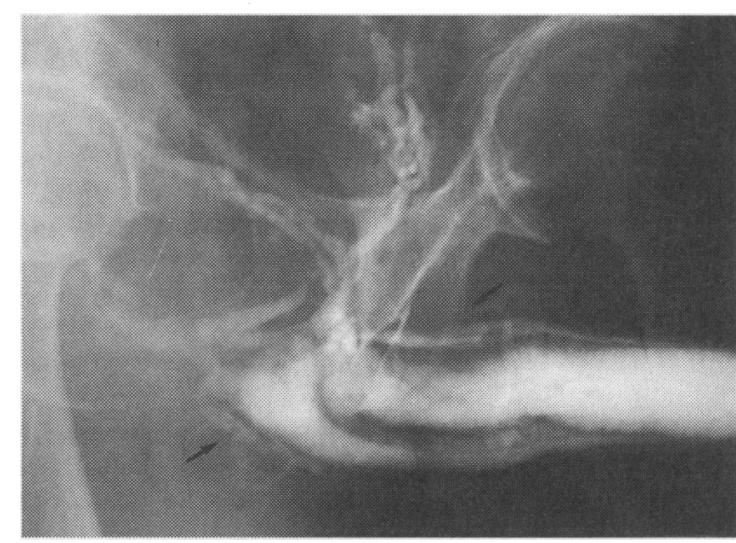

FIG 3-Cavernogram showing venous leak through the deep dorsal vein and surgically inaccessible crural veins

more invasive and only a few patients get long term benefit from penile arterial revascularisation. ${ }^{17}$

\section{Psychosexual counselling}

Psychosexual counselling is essential in treating impotence as more mechanistic approaches such as self injection pharmacotherapy or implantation of prostheses will fail in patients whose problem is primarily psychogenic. Psychosexual counselling aims at decreasing performance anxiety by increasing the range of sexual activities that do not require an erection of sufficient rigidity for penetration. To be successful it requires the close cooperation of the sexual partner. Unfortunately, there are few long term follow up series to confirm the eventual outcome of this therapy. With properly selected cases, however, good results can be achieved in the short term.

\section{Medical treatment}

The appeal of a pill for restorating potency is attested by the enormous worldwide sales of homoeopathic remedies claiming to have this effect. Unfortunately few drugs have had rigorous scientific testing and it is doubtful whether many would, in such circumstances, perform significantly better than placebo.$^{18}$ One of the few drugs that have been formally studied is yohimbine, an indole alkaloid which has $\alpha_{2}$ receptor blocking activity in vitro and is derived from the bark of the Pausinystalia yohimbe tree. In a prospective double blind study in patients with organic impotence yohimbine was not very effective, ${ }^{19}$ but a similar study in patients with psychogenic erectile dysfunction showed some useful activity. ${ }^{20}$ Other orally active drugs that have $\alpha_{2}$ blocking activity are being investigated for treating psychogenic impotence, and the results look reasonably promising.

One of the most common therapeutic strategies in erectile impotence is androgen supplementation, although true hormone related sexual dysfunction is probably rare. ${ }^{21}$ In hypogonadal patients androgens can restore both libido and potency, ${ }^{22}$ but there are no data to confirm a useful therapeutic effect in patients whose free testosterone concentrations are already

\section{Treatment of impotence}

- Psychosexual counselling

- Drugs ( $\alpha_{-}$adrenoceptor blocker)

- Intracavernosal pharmacotherapy

- Venous leak correction

- Revascularisation

- Penile prostheses

- Vacuum devices 
within the normal range. Oral testosterone supplements are less effective than parenteral preparations and are also associated with a higher incidence of hepatotoxic effects. The best method of administration is depot preparations of testosterone ester, which should be given every two to three weeks; patients' serum testosterone concentration should be monitored. Patients should be warned that androgen replacement may enhance libido without improving potency and that the treatment may exacerbate or induce benign prostatic hyperplasia and prostate cancer. Close monitoring of prostate specific antigen levels and urinary flow rates is recommended before and during treatment.

\section{Intracavernosal pharmacotherapy}

The discovery in the early 1980 s that the smooth muscle relaxant papaverine ${ }^{23}$ and the $\alpha$ blocker phenoxybenzamine $e^{24}$ could produce an erection when injected intracavernosally led to an improvement in understanding the pathophysiology of impotence and provided an effective self administered treatment for many thousands of patients. ${ }^{25} 26$ Three drugs are now commonly used: papaverine $(20-80 \mathrm{mg})$, phentolamine $(2-4 \mathrm{mg})$, and prostaglandin E1 $(20-40 \mathrm{mg}$ injected intracorporeally). ${ }^{27}{ }^{28}$ Other drugs such as calcitonin gene related peptide are being evaluated..$^{29}$

The doses and types of drug used are adjusted to suit each patient. ${ }^{30}$ It is best to start with low doses of one drug (usually papaverine or prostaglandin E1) and titrate up or add further agents, or both, according to response. ${ }^{31}$ Patients with neurogenic impotence may have a prolonged response to papaverine, and their initial dose should therefore be lower (usually 10-20 $\mathrm{mg}$ ). Most patients are able to learn how to inject the drugs quite quickly if they have reasonable manual dexterity and are given a detailed instruction and information sheet.

The main side effect associated with self injection is a prolonged erection. Patients must be warned that an erection lasting longer than four hours requires pharmacological detumescence. ${ }^{30}$ This is achieved by inserting a butterfly needle into one of the corpora, aspirating $20-40 \mathrm{ml}$ of blood, and replacing this with 5$10 \mathrm{ml}$ of the diluted $\alpha_{1}$ agonist phenylephrine or noradrenaline. $\alpha$ Agonists should not be given to patients taking monoamine oxidase inhibitors as the combination can be lethal. This method of detumescence rarely fails except when the erection has been present for more than 12-24 hours. Surgical decompression by creation of a cavernospongiosus shunt may then be necessary. Other complications include the development of painless, fibrotic nodules, sometimes resulting in mild penile curvature. Peyronie's disease occasionally develops, but it is difficult to know whether this is a result of injections or whether the lesions would have occurred spontaneously anyway. Patients considering cavernosal pharmacotherapy should be warned about all these possibilities and be given clear instructions about what to do and where to go for treatment if an erection lasts for more than four hours.

\section{Surgical treatments}

Men who do not respond to or dislike the discomfort associated with self injection may benefit from surgery. Only fair results have been reported after excision and ligation of the deep dorsal vein in men with venous leakage, even if the arterial input to the corpora is normal. ${ }^{32}$ Revascularisation of the corpora is now technically feasible. It is usually achieved by anastomosing the inferior epigastric artery to a conjoined anastomosis of the dorsal penile artery and deep dorsal vein. Success rates of $50-60 \%$ have been reported in younger patients in the shorter term. ${ }^{33}$ However this microsurgery is time consuming and exacting and should be done only as part of clinical research. Consistently good long term results have been reported with penile prostheses in properly selected and fully informed patients. The semirigid devices are difficult to conceal, and inflatable versions are now usually used. The latest two and three component inflatable devices provide good patient and partner satisfaction, ${ }^{34}$ but as they cost $£ 2000-£ 3000$ they are not suitable for everyone. $^{35}$ Nor are they a panacea for all potency problems; expectations that penile prostheses will reinvigorate an already failing relationship nearly always prove unrealistic.

\section{Vacuum devices}

Vacuum devices are a non-invasive, inexpensive, and simple treatment for men who do not respond to intracavernosal injection. ${ }^{36}$ Some patients complain that the erection produced is cold and lifeless, and the ring necessary to retain the erection may cause discomfort, especially during ejaculation. Good manual dexterity is needed to use them satisfactorily. Nevertheless they do work well for some people, are available with a money back guarantee, and are particularly useful in the older and less fit men.

\section{Conclusions}

In the current climate of limited resources for health care some people may contest the relevance of these recent advances in the treatment of impotence. The condition, however, can greatly affect quality of life. Most men want a sympathetic interview with a clear explanation of the problem and informed advice about self administered treatments. More education is required to counter the considerable ignorance and misinformation concerning impotence not only among the general public but among doctors, who are often reluctant to discuss sexual matters with their patients. In addition more studies are needed to evaluate the clinical value of the diagnostic tests available and establish the long term outcome medical and surgical interventions.

1 Furlow WL. Prevalence of impotence in the United States. Medical Aspects of Human Sexuality 1985;19:13-6.

2 McCulloch DK, Campbell IW, Wu FC, Prescott RJ, Clarke BF. The prevalence of diabetic impotence. Diabetologia 1980;18:279-83.

3 Lerner SE, Melman A, Christ GJ. Review of erectile dysfunction: New insights and more questions. F Urol 1993;149:1246-55.

4 Lue TF, Tanagho EA. Physiology of erection and pharmacological management of impotence. $f$ Urol 1987;137:829-36.

5 Batra AK, Lue TF. Penile erection: circulatory physiology. In: Kirby RS, Carson C, Webster GD, eds. Impotence: diagnosis and management. Oxford: Butterworth-Heinemann, 1991:19-26.

6 Krane RJ, Goldstein I, Saenz De Tejada I. Medical progress: impotence. $N$ Engl f Med 1989;321:1648-59.

7 Franks S, Jacobs HS, Martin N, Nabarro JD. Hyperprolactinaemia and impotence. Clin Endocrinol 1978;8:277-87.

8 Troy K, Cuttner J, Reilly M, Grabowski G, Desnick R. Tartrate-resistant acid phosphatase staining of monocytes in Gaucher disease. Am $\mathbf{f}$ Hematol 1985;19:237-44.

9 Michael V. Arterial disease as a cause of impotence. Clin Endocrinol Metab 1982;11:725-48.

10 Medical Research Council Working Party. Adverse reactions to bendrofluazide and propranolol for the treatment of mild hypertension. Lancet 1981;ii:539-43.

11 Treatment of Mild Hypertension Research Group. A randomized, placebocontrolled trial of a nutritional-hygienic regimen along with various drug monotherapies. Arch Intern Med 1991;151:1413-23.

12 Karacan I. Clinical value of nocturnal erection in the prognosis and diagnosis of impotence. Medical Aspects of Human Sexuality 1970;4:27-34.

13 Ek A, Bradley WE, Krane RJ. Nocturnal penile rigidity measured by the snapgauge band. $₹$ Urol 1983;129:964-6.

14 Eardley I, Kirby RS, Fowler CJ. Neurophysiological testing. In: Kirby RS, Carson C, Webster GD, ed. Impotence: diagnosis and management. Oxford: Butterworth-Heinemann, 1991:109-16.

15 Lue TF, Hricak H, Marich KW, Tanagho EA. Vasculogenic impotence evaluated by high resolutiaon ultrasonography and pulsed Doppler spectrum analysis. Radiology 1985;155:777-81.

16 Amin Z, Patel U, Freidman EP, Vale JA, Kirby RS, Lees WR. Colour 
Doppler and duplex ultrasound assessment of Peyronie's disease in impotent

17 Bookstein J, Valii K, Parsons L, Kessler W. Pharmacoarteriography in the evaluation of impotence. 3 Unol 1987;137:333-7.

18 Kirby RS, Eardley I. Medical treatment of erectile dysfunction. In: Kirby RS, Carson C, Webster GD, eds. Impotence: diagnosis and management. Oxford: Butterworth-Heinemann, 1991:149-52.

19 Susset JG, Tessier CD, Wincze J, Bansal S, Malhotra C, Schwacha MG. Effect of yohimbine hydrochloride on erectile impotence: A double-blind study. $\mathcal{I}$ Urol 1989;141:1360-3.

20 Reid K, Sturridge DHC, Morales A, Condra M, Harris C, Owen J, Fenemore $\mathrm{J}$. Double-blind trial of yohimbine in treatment of psychogenic impotence. Lancet 1987; ii:421-3.

21 Wilson JD, Griffin JE. The use and misuse of androgens. Metabolism 1980;29:1278-95.

22 Bancroft J, Wu FC. Changes in erectile responsiveness during androgen replacement therapy. Arch Sex Behav 1983;12:59-62.

23 Virag R. Intracavernous injection of papaverine for erectile failure. Lancet 1982;ii:938.

24 Brindley GS. Pilot experiments on the actions of drugs injected into the human corpus cavernosum penis. Brf Pharmacol 1986;87:495-500.

25 Padma-Nathan H, Goldstein I, Payton T, Krane RJ. Intracavernosal pharmacotherapy: the pharmacologic erection program. World $\mathcal{G}$ Urol 1987;5:160-5.

26 Hollander JB, Gonzalez J, Norman T. Patient satisfaction with pharmacologic erection program. Urology 1992;39:439-41.
27 Stackl W, Hasun R, Marberger M. Intracavernous injection of prostaglandin E1 in impotent men. $f$ Urol 1988;140:66-8.

28 Lee LM, Stevenson RW, Szasz G. Prostaglandin El versus phentolamine/ papaverine for the treatment of erectile impotence: a double-blind comparison. $₹$ Urol 1988;141:54-7.

29 Djamilian M, Stief CG, Kuczyk M, Jonas U. Follow up results of combination of calcitonin gene-related peptide and prostaglandin E1 in treatment of erectile dysfunction. $f$ Urol 1993;149:1296-8.

30 Andersson KE, Holmquist F, Wagner G. Pharmacology of drugs used for treatment of erectile dysfunction and priapism. International foumal of Impotence Research 1991;3:155-72.

31 Von Heyden B, Donatucci CF, Kaula N, Lue TF. Intracavernous pharmacotherapy for impotence: selection of appropriate agent and dose. $f$ Unol 1993;149:1288-90.

32 Wespes E, Schulman C. Venous impotence: pathophysiology, diagnosis and treatment. $f$ Urol 1993;149:1238-45.

33 Goldstein I. Arterial revascularisation procedures. Sem Urol 1986;4:252-8.

34 Wilson SK, Wahman GE, Lange JL. Eleven years' experience with the ilson SK, Wahman GE, Lange JL. Eleven year
inflatable penile prosthesis. $f$ Urol 1988;139:951-2.

35 Malloy TR, Wein AJ, Carpiniello VL. Reliability of AMS M700 inflatable penile prosthesis. Urology 1986;28:385-7.

36 Witherington $R$. Vacuum constriction device for management of erectile impotence. $\mathcal{F}$ Urol 1989;141:320-2.

(Accepted 1 December 1993)

\section{Current Issues in Cancer}

\section{Cancer of the head and neck}

\author{
Jeffrey S Tobias
}

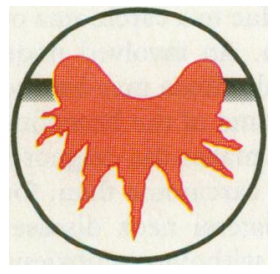

This is the fifth in a series of articles examining developments in cancer and updating what we know about the disease
The Meyerstein Institute of Clinical Oncology, The Middlesex Hospital, London W1N 8AA Jeffrey S Tobias, clinical director

Series editor: G M Mead (G M Mead is consultant in medical oncology at the Cancer Research Campaign's Wessex Medical Oncology Unit).

BMF 1994;308:961-6
Cancers of the upper aerodigestive tract, collectively known as head and neck cancers, arise from a multiplicity of sites. In the West, excess tobacco and alcohol consumption are the most important of the known predisposing factors; elsewhere in the world, notably in India and China, the aetiology, pattern of primary sites, and clinical behaviour are different. Clinically these tumours pose exceptional problems in management, and skilled multidisciplinary teams are necessary in order to achieve the highest level of service and research. Historically, surgery and radiotherapy have been the most important treatment modalities; chemotherapy is now increasingly employed but not yet fully established. Successful rehabilitation of patients with head and neck cancers requires access to high quality speech therapists and other support staff with training in functional pharyngeal disorders. Current research efforts are largely directed towards defining the proper role of chemotherapy and assessing the possible advantage of unconventional radiation approaches. In recent years the roles of primary, reconstructive, and salvage surgery have also become better defined. Many patients are suitable for randomisation into ongoing prospective clinical trials which have been specifically designed to address these issues.

Despite improvements in oral and dental hygiene together with a greater understanding of the pathogenesis of head and neck cancers, these tumours remain numerically important throughout the world and are among the most difficult to treat. In the Western World they account for around 5\% of all cancers, ${ }^{12}$ but many are either locally advanced or associated with neck lymphadenopathy at presentation, making cure less likely. In other parts of the world, notably India and southern China, cancers of the head and neck are the commonest cancers of all. As this article covers the malignancies of the upper aerodigestive tract generically referred to as "head and neck cancers" I will not discuss the presentation or management of salivary gland or thyroid carcinomas, or of sarcomas, lymphomas, and other tumours presenting at head and neck sites.

Risk factors for head and neck cancer include tobacco (whether smoked, chewed, or inhaled as snuff), alcohol, and dietary factors, with strong evidence that alcohol and tobacco consumption are synergistic (table I). Increasing trends in overall alcohol consumption are probably the main cause of the increased incidence of oral cancer in parts of Europe and the United States. ${ }^{3}$ Dietary factors are assuming increasing importance as well, particular attention now being focused on vitamin $A$ and $C$ concentrations. ${ }^{4}$

TABLE I-Relative risk of oral and pharyngeal cancer in men by cigarette smoking and alcohol consumption

\begin{tabular}{|c|c|c|c|c|c|}
\hline \multirow[b]{2}{*}{ Cigarette smoking status } & \multicolumn{5}{|c|}{ Drinks per week } \\
\hline & $<1$ & $1-4$ & $5-14$ & $15-29$ & $\geqslant 30$ \\
\hline $\begin{array}{l}\text { Non-smoker } \\
\text { Ex-smoker } \\
1-19 \text { Daily for } \geqslant 20 \text { years } \\
20-39 \text { Daily for } \geqslant 20 \text { years } \\
\geqslant 40 \text { Daily for } \geqslant 20 \text { years }\end{array}$ & $\begin{array}{l}1.0 \\
0.7 \\
1.7 \\
1.9 \\
7 \cdot 4\end{array}$ & $\begin{array}{l}1 \cdot 3 \\
2 \cdot 2 \\
1.5 \\
2 \cdot 4 \\
0.7\end{array}$ & $\begin{array}{l}1 \cdot 6 \\
1 \cdot 4 \\
2 \cdot 7 \\
4 \cdot 4 \\
4 \cdot 4\end{array}$ & $\begin{array}{r}1 \cdot 4 \\
3 \cdot 2 \\
5 \cdot 4 \\
7 \cdot 2 \\
20 \cdot 2\end{array}$ & $\begin{array}{r}5 \cdot 8 \\
6 \cdot 4 \\
7 \cdot 9 \\
23 \cdot 8 \\
37 \cdot 7\end{array}$ \\
\hline
\end{tabular}

Data from Cancer Research Campaign. ${ }^{22}$

Most head and neck cancers are squamous cell carcinomas of varying degrees of differentiation, though nasopharyngeal carcinomas-so common in Hong Kong, Canton, and other parts of southern China, northern Africa, and elsewhere-are typically less well differentiated and clearly follow a natural course rather different from that of the other main types. Almost all of the major sites (fig 1) occur more commonly in men, though with increasing use of alcohol and tobacco by women this distinction is bound to decrease, as in carcinoma of the bronchus. At present the male to female ratio for laryngeal carcinoma remains close to $10: 1$, as compared with about $2: 1$ for most other sites and a continuing slight female preponderance for postcricoid carcinoma. A few occupational causes have been identified, notably the unusual nasal fossa adenocarcinoma associated with the hardwood furniture industry.

There is increasing evidence that viruses may contribute to causation. ${ }^{5}$ Infection with the EpsteinBarr virus is clearly associated with nasopharyngeal carcinoma, and DNA from the human papillomavirus has also been detected in head and neck cancers. In some patients, notably those with oral lesions, there is a 